\title{
Global neurosurgery: current and potential impact of neurosurgeons at the World Health Organization and the World Health Assembly. Executive summary of the World Federation of Neurosurgical Societies-World Health Organization Liaison Committee at the 71st World Health Assembly
}

\author{
Gail Rosseau, MD, ${ }^{1}$ Walter D. Johnson, MD, MBA, MPH, ${ }^{2}$ Kee B. Park, MD, ${ }^{3}$ \\ Miguel Arráez Sánchez, MD, PhD, ${ }^{4}$ Franco Servadei, MD, ${ }^{5}$ and Kerry A. Vaughan, MD 3,6

\begin{abstract}
${ }^{1}$ Midwest Neurosurgical Associates, Oak Brook, Illinois; ${ }^{2}$ Emergency and Essential Surgical Care Programme, World Health Organization, Geneva, Switzerland; ${ }^{3}$ Global Neurosurgery Initiative, Program in Global Surgery and Social Change, Harvard Medical School, Boston, Massachusetts; " ${ }^{2}$ epartment of Neurosurgery, Regional University Hospital of Malaga, Spain; ${ }^{5}$ Department of Neurosurgery, Humanitas University, Milan, Italy; and ${ }^{6}$ Department of Neurosurgery, Hospital of the University of Pennsylvania, Philadelphia, Pennsylvania
\end{abstract}

\begin{abstract}
Since the creation of the World Health Organization (WHO) in 1948, the annual World Health Assembly (WHA) has been the major forum for discussion, debate, and approval of the global health agenda. As such, it informs the framework for the policies and budgets of many of its Member States. For most of its history, a significant portion of the attention of health ministers and Member States has been given to issues of clean water, vaccination, and communicable diseases. For neurosurgeons, the adoption of WHA Resolution 68.15 changed the global health landscape because the importance of surgical care for universal health coverage was highlighted in the document. This resolution was adopted in 2015, shortly after the publication of The Lancet Commission on Global Surgery Report titled "Global Surgery 2030: evidence and solutions for achieving health, welfare and economic development." Mandating global strengthening of emergency and essential surgical care and anesthesia, this resolution has led to the formation of surgical and anesthesia collaborations that center on WHO and can be facilitated via the WHA. Participation by neurosurgeons has grown dramatically, in part due to the official relations between WHO and the World Federation of Neurosurgical Societies, with the result that global neurosurgery is gaining momentum.
\end{abstract}

https://thejns.org/doi/abs/10.3171/2018.7.FOCUS18295

KEYWORDS global neurosurgery; global surgery; incidence; workforce; capacity; World Health Assembly; WHA; World Health Organization; WHO; World Federation of Neurosurgical Societies; WFNS

$\mathrm{T}$ HE World Health Organization (WHO) is the world's highest body governing global health policy. Convened annually in Geneva, Switzerland, near WHO headquarters, the World Health Assembly (WHA) is the forum through which the health ministers of the 194 Member States of WHO discuss global policy questions and approve WHO's program of work and its budget. Since its first meeting in 1948, the WHA has become the major platform for global health initiatives, with remarkable gains made in morbidity and mortality from common medical conditions. Access to surgical care, however, was long considered a luxury in many low- and middle-income countries (LMICs), where progress has stagnated or even regressed in the past 25 years.

The perception of surgery as the "neglected stepchild of public health" led to the launch of The Lancet Commis-

ABBREVIATIONS LMICs = low- and middle-income countries; WFNS = World Federation of Neurosurgical Societies; WHA = World Health Assembly; WHO = World Health Organization.

ACCOMPANYING EDITORIAL DOI: 10.3171/2018.7.FOCUS18363.

SUBMITTED June 1, 2018. ACCEPTED July 2, 2018.

INCLUDE WHEN CITING DOI: 10.3171/2018.7.FOCUS18295. 
sion on Global Surgery. In April 2015, the Commission reported 5 key messages: 1) 5 billion people do not have access to safe, affordable surgical and anesthesia care; 2) 143 million additional surgical procedures are needed in LMICs each year to save lives and prevent disability; 3 ) 33 million people face catastrophic health expenditures for surgery and anesthesia each year; 4) investing in surgical services in LMICs is affordable, but without such investments, LMICs will experience losses in economic productivity from 2015 to 2030 that are estimated to amount to US\$12.3 trillion; and 5) surgery is an indivisible, indispensable part of health care. ${ }^{2,11,17}$ The publication of The Lancet Commission on Global Surgery Report was followed shortly by the passage of WHA Resolution 68.15-"Strengthening emergency and essential surgical care and anaesthesia as a component of universal health coverage." 20 The unanimous adoption of this resolution by Member States has launched a concerted effort to advance surgical care, including neurosurgical care.

\section{Current Capacity and Deficit in Essential Neurosurgical Care}

Dewan et al. recently reported the estimate of the global volume of neurosurgical diseases, as well as the number and the distribution of neurosurgeons worldwide. ${ }^{6}$ They calculated an operative deficit of 5 million neurosurgical cases per annum, with traumatic brain injury, stroke-related conditions, tumors, hydrocephalus, and epilepsy comprising the majority of the global neurosurgical disease burden. ${ }^{4,5,7-10,14,15,18}$ They further estimated that 23,300 additional neurosurgeons are needed to address the deficit, mostly in Africa and Southeast Asia.

Ongoing efforts by neurosurgical professional associations and philanthropic foundations partially address these deficits, but the gaps in human health resources and access to treatment facilities is so significant that national policy changes are needed-especially in LMICs-to address these urgent needs. ${ }^{1,3,12,13,19}$ Participation in the WHA provides yet another avenue for advocacy at the broadest level, as well as partnering with other groups that focus on trauma prevention and treatment, emergency services, and surgical capacity.

\section{Neurosurgical Organizations and Partnerships at the WHA}

Many nongovernmental organizations (NGOs) in official relations with WHO attend the WHA to monitor reports and voting, as well as to make statements during the proceedings to support particular issues. Neurosurgeons representing the World Federation of Neurosurgical Societies (WFNS), the WFNS Foundation, and the International College of Surgeons have attended the 2017 and 2018 WHAs. The WHA serves as a meeting place for potential allies, such as other allied health professionals, public and private sector partners, and health economists. Although WHO programs can be contacted anytime and are responsive to contact, the WHA provides an important platform for neurosurgeons to connect in person with the offices within WHO that are concerned with health issues related to neurosurgery. These include the Emergency and Essential Surgical Care Programme; the Department for Management of Noncommunicable Diseases, Disability, Violence, and Injury Prevention; Maternal, Child, and Adolescent Health; Essential Medicines and Medical Devices; and the Mental Health Programme, which includes Neurology and Public Health.

\section{Activities of Neurosurgical Interest at WHA 2018}

In just 2 years, neurosurgical participation in the WHA has increased from 1 observer to nearly 20 active participants. Prior to the 2018 WHA, a boot camp for interested participants and observers was held at the American Association of Neurological Surgeons (AANS) annual meeting. The structures of the WHA and WHO were presented; the schedule of official, technical, and off-site conferences was reviewed; and effective advocacy strategies were discussed. ${ }^{16}$

The most recent WHA, held May 21-25, 2018, did not include a report on progress toward implementation of WHA 68.15, now required biennially from the WHO Secretariat. The next report, due in 2019, will serve to keep the spotlight on surgical care within the WHA agenda. Some neurosurgeons who attended this year were able to meet with their health ministries during the WHA, and will be participating in national data collection as these reports are prepared for the 72nd WHA in 2019. Clearly, data collection and analysis are the first steps toward informing national policies that can impact neurosurgical training and practice. Early collaborative steps were made to expand an open-access neurosurgeon-created partnering database, Intersurgeon (www.intersurgeon.com), for sharing training, equipment, and other resources with the rest of the global surgery community. A curriculum was designed for a future course in advocacy and global neurosurgical skills.

The strong and growing neurosurgical presence at the 71st WHA firmly positions neurosurgeons to be key partners in the scaling up of emergency and essential surgical care and anesthesia in the developing world. Neurosurgeons who collaborate with WHO, for example by participating in the WHA, will continue to foster advocacy campaigns and trauma prevention efforts, design policies to improve emergency services and surgical care delivery, and help set the global health agenda so that people worldwide will have access to safe, timely, and affordable surgical and neurosurgical care. Although the WHA is not the sole platform for impacting global policy, it provides an efficient forum for key stakeholders, including governments and nonstate actors, to discuss global health strategies.

\section{Discussion and Opportunities for Neurosurgical Participation in the WHA}

Walter Johnson, Emergency and Essential Surgical Care Programme Lead at WHO, is a neurosurgeon and welcomes volunteer neurosurgeons to learn about the collaborative process with WHO. Activities of this program 
include promoting national surgical policies, improving surgical education and training, building quality and safety, research using surgical analysis tools, resourcestratified treatment algorithms, building a network of WHO Collaborative Centers for Surgery and Anesthesia worldwide, and advocating for the surgical workforce and patients.

The WFNS represents 118 neurosurgical member societies, with more than 49,000 members. ${ }^{16}$ Founded in 1955 to promote global improvement in neurosurgical care, the WFNS has long worked to build neurosurgical capacity through education, technology, and research. As a nonstate actor in official relations with WHO, the WFNS is well positioned to champion access to neurosurgical training and care as a public health issue, to contribute to the knowledge base essential to this effort, and to form collaborative partnerships with other specialties and federal and global health agencies.

The WHO-WFNS Liaison Committee is actively working with WHO to advance access to quality care for neurosurgical patients. Membership in the Committee is open to all interested neurosurgeons who are members of WFNS member societies. The committee has no budget and all expenses are borne by individual committee members. In addition, neurosurgeons may participate as members of other nonstate actors, such as the International College of Surgeons, in official relations with WHO.

National and regional neurosurgical societies play an important role in advancing the global neurosurgical agenda. In LMICs, contributions include advocating for collection of data on the neurosurgical disease burden and accurate reporting of human health resources, and may also include evaluation of resource-stratified interventions, policies, and equipment. Professional associations in high-income countries may train and organize volunteer neurosurgeons to support local training, as well as conduct bidirectional educational exchanges and research initiatives. These combined neurosurgical voices will present the most effective advocacy to health ministers of WHO Member States.

\section{Conclusions}

The WHA has become an important annual forum within the broader strategy for advancement of global neurosurgery. Participation accelerates progress toward the goal of increasing access to safe, timely, and affordable neurosurgical care worldwide, particularly in LMICs. Neurosurgeons should continue to expand their activities with WHO and should consider attending the WHA to 1) advocate on behalf of our colleagues and their patients in regions with significant gaps in access to neurosurgical care, 2) design policies to improve delivery of neurosurgical care within the setting of universal health coverage, and 3) participate in advancing the global health agenda of WHO and its Member States.

\section{Acknowledgments}

We are grateful to the members of the neurosurgical team who, at their own expense, participated in WHA 2018: Andrea Bartoli, Angelica Clavijo, Ling Feng, Emmanuel Gay, William Harkness,
Tariq Khan, James Johnston, Marc Levivier, Richard Moser, Kee B. Park, Moody Qureshi, Andres Rubiano, Karl Schaller, and Kerry Vaughan. The following neurosurgeons participated as representatives of the International College of Surgeons: Aij-Lie Kwan and Izabela Chudzicka. In addition, Ms. Teresa Chen and Ms. Ling Yi from the WFNS Central Office in Nyon, Switzerland, provided administrative support.

\section{References}

1. Albright AL: Reflections on developing pediatric neurosurgery in Sub-Saharan Africa. J Neurosurg Pediatr 18:127138,2016

2. Alkire BC, Raykar NP, Shrime MG, Weiser TG, Bickler SW, Rose JA, et al: Global access to surgical care: a modelling study. Lancet Glob Health 3:e316-e323, 2015

3. Andrews RJ, Quintana LM: Neurosurgical care for oneneurosurgical care for all: global neurosurgical care has global benefits! World Neurosurg 85:22-24, 2016

4. Bell JS, Koffie R, Rattani A, Dewan MC, Baticulon R, Qureshi M, et al: Global incidence of brain and spinal tumors by geographic region and income level, presented at the Congress of Neurological Surgeons Annual Meeting, Boston, 2017 (Poster) (http://2017.cns.org/posterbrowser.aspx) [Accessed August 14, 2018]

5. Dewan MC, Rattani A, Baticulon RE, Faruque S, Johnson WD, Dempsey RJ, et al: Operative and consultative proportions of neurosurgical disease worldwide: estimation from the surgeon perspective. J Neurosurg 19:1-9, 2018

6. Dewan MC, Rattani A, Fieggen G, Arraez MA, Servadei F, Boop FA, et al: Global neurosurgery: the current capacity and deficit in the provision of essential neurosurgical care. Executive Summary of the Global Neurosurgery Initiative at the Program in Global Surgery and Social Change. J Neurosurg [epub ahead of print April 27, 2018. DOI: 10.3171/2017.11.JNS171500]

7. Dewan MC, Rattani A, Gupta S, Baticulon RE, Hung YC, Punchak M, et al: Estimating the global incidence of traumatic brain injury. J Neurosurg 84:1-18, 2018

8. Dewan MC, Rattani A, Mekary R, Glancz LJ, Yunusa I, Baticulon RE, et al: Global hydrocephalus epidemiology and incidence: systematic review and meta-analysis. J Neurosurg 37:1-15, 2018

9. Hughes JD, Bond KM, Mekary RA, Dewan MC, Rattani A, Baticulon R, et al: Estimating the global incidence of aneurysmal subarachnoid hemorrhage: a systematic review for central nervous system vascular lesions and meta-analysis of ruptured aneurysms. World Neurosurg 115:430-447, 447. e1-447.e7, 2018

10. Kumar R, Lim J, Mekary RA, Rattani A, Dewan MC, Sharif SY, et al: Traumatic spinal injury: global epidemiology and worldwide volume. World Neurosurg 113:e345-e363, 2018

11. Meara JG, Leather AJM, Hagander L, Alkire BC, Alonso N, Ameh EA, et al: Global surgery 2030: evidence and solutions for achieving health, welfare, and economic development. Lancet 386:569-624, 2015

12. Park KB, Johnson WD, Dempsey RJ: Global neurosurgery: the unmet need. World Neurosurg 88:32-35, 2016

13. Punchak M, Mukhopadhyay S, Sachdev S, Hung YC, Peeters S, Rattani A, et al: Neurosurgical care: availability and access in low-income and middle-income countries. World Neurosurg 112:e240-e254, 2018

14. Ravindra V, Senglaub S, Rattani A, Park KB, Dewan MC, Shrime MG: Degenerative lumbar spine disease: estimating global incidence and worldwide volume. Global Spine $\mathbf{J}$ [in press], 2018

15. Robertson FC, Lepard JR, Davis MC, Mekary R, Yunusa I, Dewan MC, et al: Epidemiology of central nervous system infectious diseases: a meta-analysis and systematic 
review with implications for neurosurgeons worldwide. J Neurosurg [epub ahead of print June 15, 2018. DOI: 10.3171/2017.10.JNS17359]

16. Rosseau GL: Report to Neurosurgeons on the World Health Assembly (WHA). Vaud, Switzerland: World Federation of Neurosurgical Societies, 2017. (https://www.wfns. org/newsletter/19) [Accessed August 14, 2018]

17. Shrime MG, Bickler SW, Alkire BC, Mock C: Global burden of surgical disease: an estimation from the provider perspective. Lancet Glob Health 3 (Suppl 2):S8-S9, 2015

18. Vaughan KA, Ramos CL, Buch VP, Mekary RA, Amundson JR, Shah M, et al: An estimation of global volume of surgically treatable epilepsy based on a systematic review and meta-analysis of epilepsy. J Neurosurg [epub ahead of print September 14, 2018. DOI: 10.3171/2018.3.JNS171722]

19. Warf BC: "Who is my neighbor?" Global neurosurgery in a non-zero-sum world. World Neurosurg 84:1547-1549, 2015

20. World Health Organization: WHA Resolution 68.15:

Strengthening emergency and essential surgical care and anaesthesia as a component of universal health coverage. WHO.int. (http://apps.who.int/gb/ebwha/pdf_files/WHA68/ A68_R15-en.pdf?ua=1) [Accessed August 14, 2018]

\section{Disclosures}

Dr. Johnson is employed by WHO; this report does not necessarily reflect official WHO opinions. Dr. Rosseau is the appointed chairman of the WHO-WFNS Liaison Committee and receives no compensation for any committee activity.

\section{Author Contributions}

Conception and design: Vaughan, Rosseau. Analysis and interpretation of data: Rosseau. Drafting the article: Vaughan, Rosseau, Park. Critically revising the article: all authors. Reviewed submitted version of manuscript: all authors. Approved the final version of the manuscript on behalf of all authors: Vaughan. Study supervision: Rosseau, Johnson.

\section{Correspondence}

Kerry A. Vaughan: Harvard Medical School, Boston, MA. kerry. vaughan@uphs.upenn.edu. 